Article

\title{
Subjective Evaluation of Media Content as a Moderator of Media Effects on European Identity: Mere Exposure and the Hostile Media Phenomenon
}

\author{
Waqas Ejaz ${ }^{1, *}$, Marco Bräuer ${ }^{2}$ and Jens Wolling ${ }^{1}$ \\ ${ }^{1}$ Empirical Media Research and Political Communication Department, Technical University of IImenau, 98693 IImenau, \\ Germany; E-Mails: mian-waqas.ejaz@tu-ilmenau.de (W.E.), jens.wolling@tu-ilmenau.de (J.W.) \\ ${ }^{2}$ Federal Office for the Family and Civil Society, 02959 Schleife, Germany; E-Mail: marcobraeuer@me.com \\ * Corresponding author
}

Submitted: 30 January 2017 | Accepted: 27 March 2017 | Published: 5 May 2017

\begin{abstract}
This paper posits that the concept of European identity is an important indicator of the legitimacy of the European Union (EU). It further assumes that the exposure to EU related media content can influence the feeling of European identity. In order to verify this assumption, we combined the mere-exposure-theory and the hostile media phenomenon. We assume that these theoretical concepts could help to understand the influence of media on people's levels of attachment to the EU. Regression analyses are performed on secondary data that were collected in a Eurobarometer survey in 2013. Our findings revealed that media exposure affected the respondents' identification with Europe, as well as the modifications of this effect based on their assessments of EU media coverage. The results of the current study not only validate assumptions about the mere-exposure effects on identity but also confirm the theoretical assumption that perceived hostility reduces such effects, whereas exposure to information that is perceived as neutral promotes the effects of media exposure on the feeling of European identity.
\end{abstract}

\section{Keywords}

collective identity; European identity; hostile media; mere-exposure effect

\section{Issue}

This article is part of a multidisciplinary issue of Media and Communication, edited by Epp Lauk (University of Jyväskylä, Finland) and Raul Reis (Emerson College, USA).

(C) 2017 by the authors; licensee Cogitatio (Lisbon, Portugal). This article is licensed under a Creative Commons Attribution 4.0 International License (CC BY).

\section{Introduction}

The idea that European polity requires a collective identity of the European citizens in order to support the process of European integration is not new. Already in 1973 a normative concept of identity was introduced into the European political discourse during the Copenhagen European Commission Summit (European Commission, 1973). Today, it is often argued by scholars that developing and strengthening European identity is necessary to bolster the achievements of the integration process (De Vreese \& Boomgaarden, 2006; Triga \& Vadratsikas, 2016) and that it might even help to legitimize further European integration (Bruter, 2005). This assumed capac- ity of European identity prompted many political scholars to investigate the relationship of identity with several key political concepts such as democracy and citizenship (Habermas \& Derrida, 2005), Europeanisation (Harmsen \& Wilson, 2000; Risse, 2010), European Union (EU) foreign policy (Manners, 2002), Euroscepticism (Hooghe \& Marks, 2005; Szczerbiak \& Taggart, 2008), and migration (Favell \& Recchi, 2009).

Despite being rigorously investigated, a unanimous definition of European identity is still not available, because the concept is used in varied contexts and for different purposes. That is why the term European identity is described in various ways such as "flexible" (Walkenhorst, 2008, p. 4), "abstract" (Stråth, 2002) and "hybrid" 
(Maier \& Risse, 2003, p. 29). Studying and researching European identity is particularly problematic because as an idea, European identity leaves open a myriad of options for interpretation. In parts of the literature, European identity is interpreted as a necessary precondition, for political integration, because at citizen's level it promises to foster solidarity and active participation (Walkenhorst, 2009). On the other hand, it is also considered vital because it promotes legitimacy and increase effectiveness of the political system (Kaina \& Karolewski, 2013). Contrary to the positive connotation of identity, the literature also highlights the contested characteristics of identity (Brubaker \& Cooper, 2000, p. 1; Gandemer, 2014), and such contestation does not only exist in the interpretation of the concept, but it is also present in the debate of how it can be developed (Stone Sweet, Sandholtz, \& Fligstein, 2001; Wendt, 1999) along with its complementary (Agirdag, Phalet, \& Van Houtte, 2016; Delanty, 2014) or tense relationship with national identity (Carey, 2002).

Regardless the divergent interpretations of European identity, it remains a key-concept for the investigation of the future of EU. That is why researchers from diverse fields continue to investigate the topic and reveal its varied manifestations. Besides political and social scientists, also communication scholars are involved in investigations related to European identity. Because citizens become involved in European politics mainly through the media, it is reasonable to expect that European identity - understood as a political concept-is influenced by the exposure to EU-related media coverage. The "Brexit" might be considered as a recent example of the influence media may have on identity. At least it was intensely debated in the media whether the coverage on "Brexit" was biased (Reuters Institute for the Study of Journalism, 2016) and cultivated national boundaries rather than a common European identity (Corbett, 2016). In spite of the widespread assumption that media impact identity, the research on the effects of media on European identity is still rare, with view exceptions (for overviews see, Bruter, 2005; De Vreese \& Boomgaarden, 2006; De Vreese, Boomgaarden, \& Semetko, 2011; Olausson, 2010; Staehelin, 2016; Triga \& Vadratsikas, 2016). Therefore, the purpose of this paper is to broaden this field of research.

In the light of above arguments, the main goal of this study is to clarify the influence of the exposure to European political news on identification with the EU. Consequently, we first define the concept of European identity and then examine the current research that explores the effects of media on European identity. In addition, we highlight the research gaps in the field. In the subsequent section, we focus on two theoretical conceptsmere exposure and hostile media perceptions-both of which have not been employed within the context of European identity. Based on these theoretical approaches, we develop hypotheses concerning the effects of media exposure on identity and the intervening effects of media perception and tested them with the help of a sec- ondary data analysis. The results of this analysis reveal a connection between mere-exposure effects and hostile media perceptions with regard to European identity. In the final section, the results are discussed, the limitations of the research are considered, and recommendations for future research are specified.

\section{Conceptualizing European Collective Identity}

Collective identity is a broad concept and not restricted to any particular aspect. Among others gender, culture, ethnicity, religion, and nationality have been considered as basis of people's identity (Irimie, 2014). With regard to the origins of such collective identities, different theoretical arguments offer contested views. One theoretical standpoint argues that identity is essentially primordial, i.e. it is constructed from kinship, cultural or historical ties that are enshrined in the collective memory of the culture (Smith, 1992). In addition, there are postmodernist scholars who posited that individuals perceive that they have something in common on the basis of which they form an "imagined ommunity". For these scholars cultural and geographical constraints do not really matter (Anderson, 1991). Contrary to the aforementioned understandings, a third theoretical approach draws inspiration from modernist school of thought which argues that European identity is an elusive, socially constructed and negotiated reality, something that has a different meaning for each individual and does not really rely on common past (Gellner, 1983).

Within the context of this paper, European identity is considered as a form of socially constructed collective identity of the Europeans. This sense of collective identity is not developed separately within each individual, but is socially constructed, which means it emerges as the intentional or unintentional consequence of social interactions (Fligstein, Polyakova, \& Sandholtz, 2012, p. 108). European identity is based on the subjective feeling and sense of belonging together as Europeans. However, this paper is focused only on the political nature of European collective identity.

In the political science literature, Easton (1965, p. 185) termed collective identity as the "we-feeling" and regarded it as a necessary condition for individuals who want to cooperate politically and authorize certain representatives to act and rule on their behalf. Hence, identity is the primary source of the legitimization of any political community and structure. Thus, in the context of this paper, it can be argued that Europeans are required to have such sense of community and belonging to EU, which consequently foster European collective identity.

Without such an attachment, any governmental regime could be considered illegitimate. In a similar vein, John Stuart Mill (1861, p. 391) argued that collective identity is a necessary aspect of democratic decisionmaking. Consequently, the legitimacy of a new political structure depends on an explicit and implicit agreement that links the political community to its citizens and gives 
it fundamental institutional acceptability (Bruter, 2003). In this context it is of high importance to understand that different forms of collective identities do not have to be in a conflictual relationship (for overviews see Delanty \& Rumford, 2005, p. 51; Risse, 2003; Ruiz, et al., 2004, p. 2). For example, it is possible to have a very strong national identity and at the same time to be strongly attached to Europe (e.g. Ruiz et al., 2004, p. 8). This fact is taken into account by various models of the relationship among national and European identities, e.g. models of nested identities, concentric circles, layer cake, crosscutting identities or marble cake (Risse, 2010).

Despite these divergent views, scholars neither concede that collective identity is not significant. Consequently, researchers are interested in the factors influencing the development of collective identities. The following section of the paper narrows the scope and outlines the impact of media on European identity.

\subsection{The Nature and Impact of EU Media Coverage}

In the debate on the development of European identity, it is imperative to understand the role of media, because primarily media serve at the heart of (re)construction process of European identity (Schneeberger, 2009). Due to the lack of first-hand experiences of politics, whether domestic, European, or international, citizens depend heavily on the mass media to obtain information about political matters (Ball-Rokeach \& Defleur, 1976), which in turn affects their political attitudes (Rittberger \& Maier, 2008).

Outlining the pre-requisites of identity formation, Thompson (1995, p. 186) argued that "identity requires symbolic material for its maintenance, growth and transformation". In the processes of identity formation, the news media play a relevant role because of their ability to (re)produce symbolically certain perspectives on the world and our place in it (Olausson, 2010). They "have become organised mechanisms of great significance for constructing identities in local, national and transnational contexts within modernity" (Georgiou, 2006, p. 11). A second precondition for European identity to take root is its establishment as a conversational "habit", within general public discourses, and media play a crucial role in this regard (Gripsrud, 2007, p. 490) by continuously placing certain issue on its agenda.

To understand the role of the media for European integration and European identity much research is done on the characteristics of the European media system and on media coverage related to the EU. Results show the absence of an influential pan-European media outlet. This indicates that "the EU as a political structure lacks a corresponding communication system" (KaitatziWhitlock, 2007, p. 687). Consequently, the representation of the EU in the media depends on national media outlets, which are not always Brussels' "best friends" (Gerhards, Odfferhaus, \& Roose, 2009; Hillje, 2013). This deficiency significantly affects the provided image of the
EU. Kaitatzi-Whitlock (2007) characterized the reportage of EU affairs in national media as scattered, offering only minimal visibility, and having national biases; moreover, the coverage usually has a focus on personalization and "ethno-controversial" issues.

Norris (2000) found that coverage of EU affairs in TV news between 1995 and 1997 was with mostly neutral or negative tone. Similarly, De Vreese (2004) reported findings that EU actors were often not evaluated in the news; but, when they were judged, the tone was negative. Findings from Peter, Semetko and De Vreese (2003) showed that most of the national TV coverage of the $\mathrm{EU}$ is neutral. Another analysis on media representation of EU in selected member states reported mixed media coverage (Alarcón, 2010). More positive accounts concerning the evaluation of the EU were obtained by some studies on the quality press (Koopmans \& Statham, 2010; Trenz, 2007). Consequently, Schuck et al. (2011) summarized the state of research saying that all in all there is negative bias toward the EU albeit most of the news media coverage is neutral.

But, how this kind of coverage might influence the "we" feeling among Europeans, still remains somehow an open question. On the one hand, there is widespread confirmation of a "crucial role of media for collective identities" (Hillje, 2013, p. 7). On the other hand, it is unclear how this role looks like and what effects might appear. Because of this uncertainty one would expect intense research efforts to clarify the role of the media. But in fact media effects research on public opinion about the EU is still an "embryonic" field of study (De Vreese \& Boomgaarden, 2006, p. 421). Similarly, Rittberger and Maier (2008) stated that the literature on public opinion and EU integration has thus far neglected the role of media effects on attitudes towards feeling European.

In the literature, the few exceptions that investigate the effects of media on European identity and integration primarily focus on agenda setting, priming, and framing effects (see Semetko, 2004) or conduct elite communication discourse analysis (see Suszycki, 2006; Wodak, 2004). Elite communication discourse analyses revealed that promoting and constructing a specific identity is a "top-down" affair (Shore, 2000). However, this paradigm has shifted, and scholars now assume that identity formation is not the exclusive task of elites because it also can be constructed from the "bottom up" (Bruter, 2005). Thus, analyses should not be limited to the discourse of the elites, but the broad public also should be considered. Therefore, other methods such as surveys should also be applied in order to study "bottom-up" European identity construction.

Although there is not much research on media effects, one important finding revealed the ability of negative news to have stronger influence on political support, and European integration and identity than positive news (De Vreese et al., 2011). The stronger influence of negative news does not mean that positive news has no effect, "but overall, negative arguments win the 
day" (De Vreese et al., 2011, p. 194). Based on the findings of a more negative tendency in the coverage and the stronger effects of negative coverage on people's attitude, it seems plausible to expect that the exposure to media information about the EU would have a negative effect on European identity. In the following chapter we will unfold theoretical considerations that challenge this expectation.

\section{Theoretical Reorientation: Mere-Exposure and Hostile Media Effects}

The mere-exposure-theory suggests that people tend to develop positive attitudes towards objects merely because of the repeated exposure to these objects. No further elaboration by the individual is required (Zajonc, 2001, p. 225). The mere-exposure effect can occur without any cognitive processing, even if people are not aware that they are exposed to a specific stimulus. Therefore, recipients are not required to feel familiarity with the object (Zajonc, 2001, p. 225). The only condition is that the first experience with that object is not an explicitly negative one. These premises fit the situation of the consumption of news about European issues. Even though the general tendency of the coverage on the EU is negative, the overwhelming majority of media content is neutral. Following this argumentation, the mereexposure-theory calls into question the prospect of negative effects.

Research on the attitudes towards foreign countries has shown that the mere-exposure effect can be triggered by media use (Perry, 1990). Some evidence also supports the applicability of the idea to European identity. Studies that measured the frequency of appearance of EU topics in various national media demonstrated that the more frequently EU topics appeared the better was the breeding-ground for a sense of community and the development of "Europeanized national public spheres" (e.g., D'Haenens, 2005; De Vreese, 2007). Continuous exposure to news coverage about the EU makes people feel familiar with the EU. According to the mere-exposure effect, this perception of familiarity will lead to a stronger identification with the EU. Furthermore, this effect might be strengthened by the tendency of selected exposure (Slater, 2007).

It is evident that the assumption of a linear relationship oversimplifies the connection between media and identity because it ignores the role of the recipients' perceptions and interpretations of the media content. Studies dealing with the perceptions of news slant or bias showed that recipients, especially partisans, critically assess the news with regard to the issue of interest and claim frequently that the news media are hostile towards their own party. Therefore, a close examination of the mechanism of the perception of media biases is necessary.

The observation that partisans frequently perceive the media coverage on relevant issues as biased against their own position is called the hostile media phenomenon. In a seminal experimental study, Vallone, Ross and Lepper (1985) showed that the media coverage of the Beirut massacre in Lebanon was perceived as biased by both, the pro-Israeli group and the pro-Arab group. Moreover, experimental and survey studies have continuously replicated previous findings on hostile media perceptions. Hence, it can be taken for granted that there is a "tendency for individuals with a strong existing attitude on an issue to perceive that ostensibly neutral, evenhanded media coverage of the topic is biased against their side and in favor of the antagonist's view" (Perloff, 2015, p. 707). Recently, a meta-analysis of 34 hostile media studies concluded that stronger partisanship leads to higher perceptions of media bias, but even at moderate partisanship levels (low involvement), hostile media perceptions are detectable (Hansen \& Kim, 2011).

Studies that investigated the hostile media phenomenon predominantly dealt with the identification of the mechanisms that cause the perception of bias (GinerSorolla \& Chaiken, 1994; Gunther \& Liebhart, 2006; Vallone et al., 1985). Only a few studies have dealt with the potential effects of hostile media perceptions, such as of the support of democracy (Tsfati \& Cohen, 2005), the estimation of the opinion climate (Gunther, Christen, Liebhart, \& Chih-Yun Chia, 2001), and the willingness to engage in discussions (Hart, Feldman, Leiserowitz, \& Maibach, 2015; Hwang, Pan, \& Sun, 2008). But none of the studies directly related to hostile media perceptions link effects of media on (political) identity, therefore, the insights contributed by this research provide some inspiring ideas for the research on the effects of media on European identity.

It could be argued that European citizens generally evaluate the performance of the EU with regard to the functioning of its institutions and the outcome of its policies. Consequently, they develop attitudes towards the EU polity. Obviously the concept of "attitudes" is not identical with concept of "partisanship", however they are related. From the body of hostile media research we can conclude that it is likely, that citizens who perceive the overall performance of the EU as (very) good would claim that the representation of the EU by news media is too negative. Furthermore, citizens who perceive the overall performance of the EU as quite negative would blame the news media for portraying the EU in an overly positive light. However, because the evaluation of an object is not the same as partisanship, it is also possible that citizens with a negative attitude towards the performance of the EU could perceive that the media draws an overly negative picture of the EU. Correspondingly, people with a positive image of EU institutions and policies might observe that news media providing an overly positive representation of the $\mathrm{EU}$.

Based on these theoretical elaborations we assume that the evaluation of the performance of the object (EU) in connection with the evaluation of the representation of the object (EU) in the media would probably moder- 
ate the strength of the mere-exposure effect. Even if according to the mere-exposure-theory, no further elaboration of the individual is necessary, recipients will always make judgments about the sources of information (e.g. if they perceive the media to be hostile towards an object). We assume that these judgments modify the mereexposure effect.

\section{Research Questions and Hypotheses}

Following the foregoing theoretical elaboration, two research questions are posed:

(1) Does the intensity of the exposure to news about the EU have an effect on the development of a European identity?

(2) Is this effect modified by the perception of media hostility?

The mere-exposure-theory postulates that the amount of exposure to information about the object (EU) leads to an individual's familiarization with it and hence, supports the creation of identity:

H1: The higher the exposure to news about the EU, the stronger the European identity.

Based on the theoretical assumptions and findings from hostile media research, it might be possible that hostile media perceptions modify the strength of the mere exposure effect on European identity (see Figure 1). Although the mere-exposure effect works subconsciously, it is plausible that the conscious evaluation of the representation of the stimulus could reinforce or attenuate the mere-exposure effect. If persons perceive the media as hostile, it is probable that the mere-exposure effect is weakened thus we hypothesize:
$\mathrm{H}$ 2: The mere-exposure effect is weaker in persons who perceive the media as hostile, than in persons who perceive the media as not hostile.

Furthermore, we argue that within the group of persons who perceive the media as not hostile, some might be particularly susceptible to the mere-exposure effect. We assume that among those who are not partisans and perceive the media coverage as neutral, the mere-exposure effect is even more present than among all the others without hostile media perceptions:

H3: The mere-exposure effect is strongest in nonpartisan persons who perceive the media as objective.

Taken together we assume that the weakest mereexposure effect appears in persons with hostile media perceptions, while the strongest effect appears in non-partisans who perceive the media as objective. The strength of the mere-exposure effect for the others is in between.

Furthermore, we assume that other factors also influence European identity. First of all, we assume that the evaluation of the performance of the EU has a strong direct effect on identity; those who evaluate the performance of the EU more positively will identify themselves more with Europe as others. Besides that, we will control for several socio-demographic variables like age, education or social status, which might influence identity as well. The complete model is depicted in Figure 1.

\section{Method}

To test the four hypotheses, a secondary data analysis was conducted on surveys in the Eurobarometer 80.1 series that were carried out in November 2013. The data collection was executed by TNS OPINION (Brussels) as re-

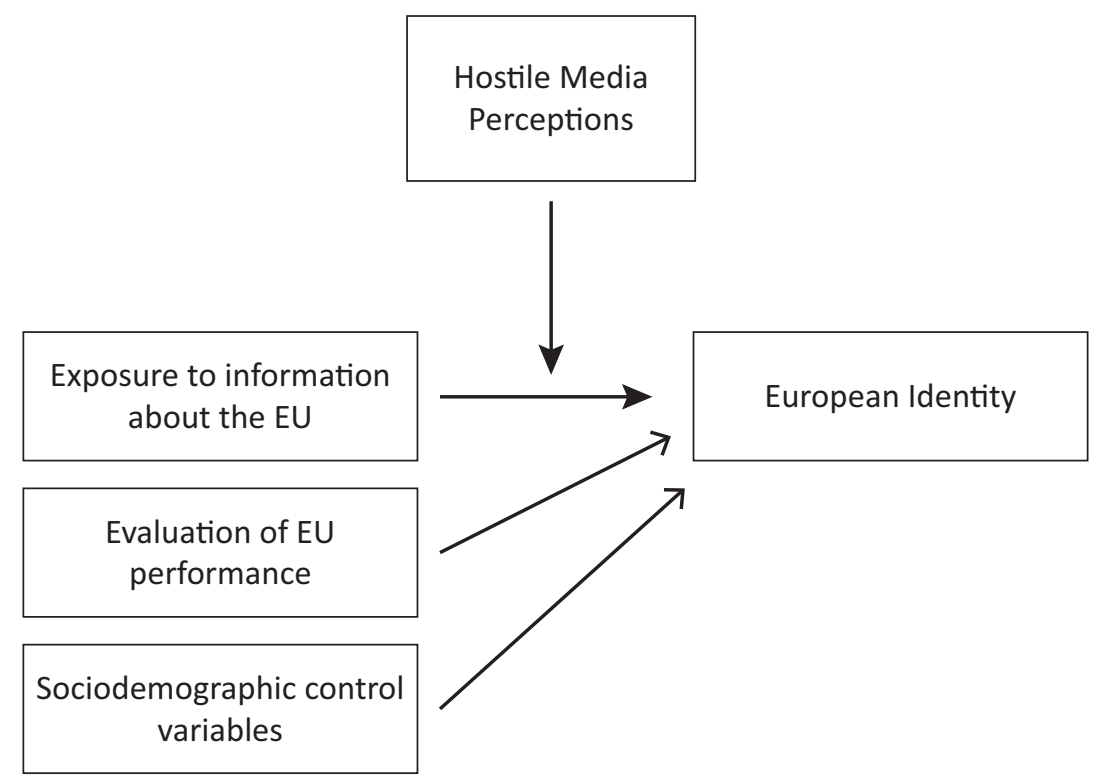

Figure 1. The variable model. 
quested by the European Commission. It consists of survey data collected from the 28 member states of the EU. Overall, data gathered from 27,829 persons were analyzed. The data were weighted before the analysis. The weighting factors adjusted the national samples for sex, age, and region according to the share in the total population aged 15 years and older in the EU.

The dependent variable (identity) was operationalized by two indicators: Citizens were asked to answer the following question: "Please tell me how attached you feel to the European Union" by using a scale from 1 (not attached at all) to 4 (very attached). Furthermore, the item "You feel you are a citizen of the EU" was used in indexbuilding. The participants were asked to indicate the extent to which this item corresponded to their own opinion. Possible answers were 1 (no, definitely not), 2 (no, not really), 3 (yes, to some extent), and 4 (yes, definitely). The two items were highly correlated $(r=.67)$, and the scale reliability was good (Alpha $=.80$ ). Thus, they were deemed suitable for index-building. Based on this index, the mean level of European identity was about 2.6, which was almost exactly in the middle of the scale (1-4). However, there were some differences in the level of European identity between the countries. The average identity in most countries was somewhere between 2.3 and 2.7. The negative outliers were Greece (2.1), Great Britain (2.2) and Cyprus (2.2) while the positive exceptions were Luxembourg (3.0), Germany (2.8) and Belgium (2.8).

The independent variable was operationalized by a combination of several items: The participants were first asked the following question: "Could you tell me to what extent you...a) watch television on a TV set or via the Internet, b) listen to the radio, c) read the written press d) use the Internet?" Possible answers were: 5 (every day/almost every day), 4 (two or three times a week), 3 (about once a week), 2 (two or three times a month), 1 (less often), 0 (never/no access to this medium). Later they were questioned: "Where do you get most of your news on European political matters? Firstly? And then?" Possible answers were respectively: Television, the Press, Radio, and the Internet. Out of these two measurements a new variable for every medium was calculated indicating if the respective medium was the first source for EU news (2), a less relevant one (1), or if the medium was not a source for EU news at all (0). Afterwards each of the four variables was multiplied with the respective mediause variable. By doing so, four variables (on a scale from 0 to 10) were obtained, each indicating the amount of EU specific input from the respective media (TV, Newspaper, Radio, Internet). Finally, an index out of these four variables was calculated indicating the overall exposure to EU-news.

To operationalize the hostile media perceptions as the intervening variable, two measurements were required. First, the perceived bias in the coverage was registered, and the evaluation of the performance of EU was traced to identify the individual standpoints of the respondents.
The perceived bias was operationalized by three items. The respondents were asked, "Do you think that the [national] television present(s) the EU too positively, objectively, or too negatively?" The same question was repeated regarding the radio and the press. The answers were coded for each variable as 1 (too negatively), 2 (objectively), and 3 (too positively). The three variables were highly correlated (between $r=.68$ and $r=.75$ ), and the scale reliability was also good (Alpha $=.88$ ); thus, the items could be used in index building. Therefore, the three variables were summed and afterwards recoded into three groups. The values 3,4 , and 5 were recoded into 1 (too negatively), value 6 was recoded into 2 (objectively), and the values 7,8 , and 9 were recoded into 3 (too positively).

In the operationalization of the individual's evaluation of the performance of EU, two items were applied for index building. The first item operationalized satisfaction "with the way democracy works in in the EU". The responses were measured on a 4-point scale: 1 (not at all satisfied), 2 (not very satisfied), 4 (fairly satisfied), and 5 (very satisfied). The second item referred to the expected future development of the EU: "At the present time, would you say that, in general, things are going in the right direction or in the wrong direction in EU?" The variable consisted of three values: 1 (things are going in the wrong direction), 3 (neither the one nor the other), and 5 (things are going in the right direction). Because the two variables were positively correlated $(r=.42)$, they were combined in an index. On the one hand this variable was introduced in the model as indicator for the "Evaluation of EU Performance" and on the other hand it was used to operationalize hostile media perceptions. Therefore, the index was recoded into three groups: 1 (negative evaluation of the EU; 1.0-2.4), 2 (neutral evaluation of the EU; 2.5-3.5), and 3 (positive evaluation of the EU; 3.6-5.0).

To identify persons with hostile media perceptions, the individual standpoint concerning the evaluation of the performance of the EU must be combined with the perceived media bias. Figure 2 shows several possible combinations of individual standpoints and media-bias perceptions. In the upper part of the figure, the combinations, which indicate a hostile media perception, are illustrated. The two other examples are of biased media perceptions, but they do not indicate the hostile media phenomenon. The evaluation of a hostile media perception requires that the person has a clear standpoint on the issue (i.e., is a partisan) and perceives the media as biased in a direction against his or her own opinion. Both requirements were met in the upper example but not in the other two examples.

Table 1 shows the combinations of the values of the two variables that indicate the different types of hostile and non-hostile media perceptions. The respective numbers of cases of the groups are shown in brackets. As Table 1 shows, the group of persons who have hostile media perceptions consists of roughly 3,900 persons (group 1). The group with a neutral standpoint and an ob- 
Positive and negative hostile media perceptions

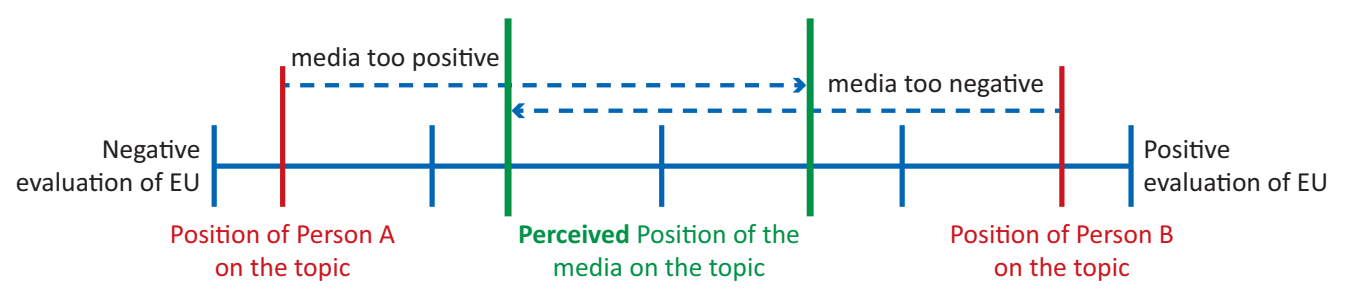

Two examples for biased but not hostile media perceptions
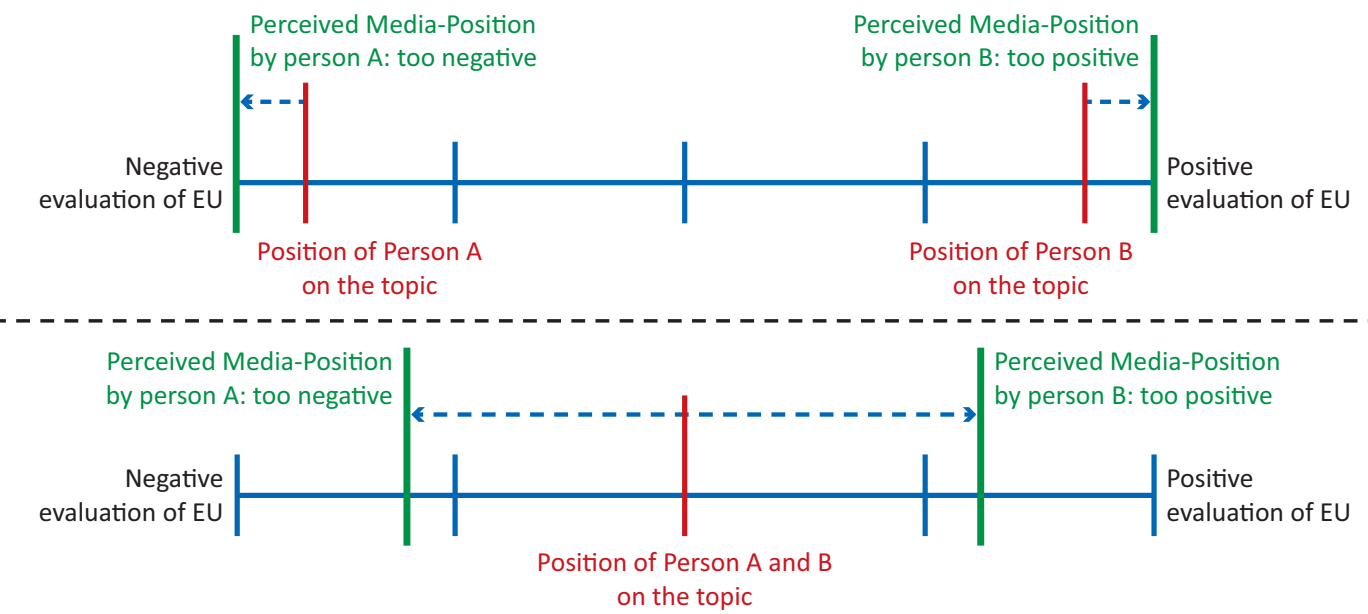

Figure 2. Hostile media perceptions vs. biased media perceptions.

Table 1. Hostile media perception (typology and number of cases).

\begin{tabular}{|c|c|c|c|c|}
\hline & & \multicolumn{3}{|c|}{ Evaluation of EU } \\
\hline & & negative & neutral & positive \\
\hline \multirow{3}{*}{$\begin{array}{l}\text { Evaluation of the way } \\
\text { the national media } \\
\text { present the EU }\end{array}$} & too negatively & $\begin{array}{c}2 \\
(n=2,156)\end{array}$ & $\begin{array}{c}2 \\
(n=1,928)\end{array}$ & $\begin{array}{c}1 \\
(n=1,099)\end{array}$ \\
\hline & objectively & $\begin{array}{c}2 \\
(n=3,990)\end{array}$ & $\begin{array}{c}3 \\
(n=5,163)\end{array}$ & $\begin{array}{c}2 \\
(n=3,997)\end{array}$ \\
\hline & too positively & $\begin{array}{c}1 \\
(n=2,810)\end{array}$ & $\begin{array}{c}2 \\
(n=1,725)\end{array}$ & $\begin{array}{c}2 \\
(n=924)\end{array}$ \\
\hline
\end{tabular}

Note: 1 = hostility perception, 2 = no hostility perception, 3 = objective media perception by non-partisans (neutrality perception).

jective perception (group 3 ) is somewhat larger (approx. $5,200)$. Because this group contrasts the groups with hostile media perceptions, their perspective is designated as a neutrality perception.

\section{Findings}

Regression analyses were conducted to test the three hypotheses. In each analysis European Identity (mean $=2.6$; on a scale from $1=$ low to $4=$ high; $\mathrm{SD}=0.8$ ) was the dependent variable and the media use index (mean $=3.4$; on a scale from $0=$ no to $10=$ high; $S D=1.3$ ) was the independent variable. Besides media use the evaluation of the performance of the EU ( mean $=2.9$ on a scale from $1=$ negative to $5=$ positive; $S D=1.3)$, age (mean $=48.9$ years; $S D=17.8)$, sex (female $=52 \%)$, education $($ mean $=19.3$ age, when formal education was finished on a scale from 10 to 40; SD $=4.5$ ), and social level (mean $=5.5$ on a scale from $1=$ lowest, to $10=$ highest; $S D=1.6$ ) were introduced as control variables in the model.

In all models, the five control variables: EUperformance, societal level, education, age and sex were controlled, but the effects are not displayed in Table 3 .

$\mathrm{H} 1$ refers to the general mere-exposure effect: The higher the exposure to news about the EU, the stronger the European identity. The hypothesis was confirmed by the results of the regression analysis (see Table 2). Despite rigorous control of further factors, a small but highly significant positive effect (beta $=.12$ ) was observed, indicating that people who have a higher exposure to EU related news have also a stronger EU iden- 
Table 2. Regression analysis: Hypothesis testing.

\begin{tabular}{lcccc}
\hline Hypothesis & $\mathrm{H} 1$ & $\mathrm{H} 2$ & $\mathrm{H}$ \\
\hline Sample & Whole & Persons who & Persons who & perceive media \\
Sample & as hostile & $\begin{array}{c}\text { perceive media } \\
\text { not as hostile }\end{array}$ & $\begin{array}{c}\text { who perceive media } \\
\text { not as hostile }\end{array}$ \\
\hline $\mathrm{n}=$ & 20,456 & 3,384 & 17,072 & 4,472 \\
$\mathrm{R}^{2}=$ & .20 & .28 & .16 & .05 \\
\hline
\end{tabular}

\begin{tabular}{lcccc}
\hline & & beta coefficients & \\
\hline Exposure to EU-News & $.12 * * *$ & $.09 * * *$ & $.14^{* * *}$ & $.15^{* * *}$ \\
\hline EU- performance & $.37^{* * *}$ & $.44^{* * *}$ & $.32 * * *$ & $.02^{* * *}$ \\
Social level & $.08^{* * *}$ & $.09 * * *$ & $.07 * * *$ & .03 (n.s.) \\
Education & $.08^{* * *}$ & $.10^{* * *}$ & $.09 * * *$ & $.11^{* * *}$ \\
Age & -.01 (n.s.) & $-.04 * *$ & -.01 (n.s.) & .01 (n.s.) \\
Sex & $-.02 * *$ & .02 (n.s.) & $-.03 * * *$ & $-.03^{* *}$ \\
\hline
\end{tabular}

Note: ${ }^{* * *}=p<.001 ;{ }^{* *}=p<.01 ;^{*}=p<.05$

tity. This positive relationship between media use and identity was observed in all European countries, and in 26 of 28 countries the effect was significant (only in the Netherlands and Hungary it was not). Among the other countries the strength of the effect varied: In Ireland and Estonia, the effects were the lowest (beta $=.07 / .08$ ) while in Germany and Malta the effects were the highest (beta $=.18 / .18$ ).

$\mathrm{H} 2$ introduces the perceived hostility as an intervening variable: The mere-exposure effect is weaker in persons who perceive the media as hostile, than in persons who perceive the media as not hostile. To test this hypothesis, the sample was divided into two parts, and the same regression was conducted in both subsamples. The first subsample consisted of those who perceived the media as hostile (group 1 in Table 1); the other groups (2 and 3) constituted the comparison sample. $\mathrm{H} 2$ was also supported by the results (see Table 2). The beta coefficient in the group of those who perceived the media as hostile was smaller (beta $=.09$ ) than in the comparison group (beta $=.14$ ).

H3 considers differential effects within the group of people without hostile media perception, positing that the mere-exposure effect is stronger in non-partisans who perceive the media as objective as in non-partisans who perceive the media as biased. To test $\mathrm{H} 3$, the sample of people without hostile media perception was divided into two parts and the regression analysis was conducted just for group 3 (see table 1 the group in the center). H3 was also supported by the results. The results show that the mere-exposure effect on non-partisans who perceived the media as objective (neutrality media perception) was (at least slightly) stronger than on all other groups (beta $=.15$ ).

To verify whether these results could be replicated in all parts of Europe, the sample was divided into three parts: seven countries with citizens having a low European identity were merged in the first group $(n=8,094)$; 14 countries with a medium level of European identity were pooled in the second group ( $n=6,994)$; the remaining seven countries, with citizens having the highest European identity, were combined in the third group $(n=8,704)$. The regression analyses (including the five control variables) were repeated in these three country groups. The findings show that the general structure of the results remained the same. Table 3 depicts the relevant effects of the exposure to EU news (beta coefficients). In each subsample the effects were lowest in the hostile subgroup, while the non-partisan group, whose members perceive the media as objective, showed the strongest effect. This finding was consistent in all subsamples. On the other hand, the effect-strengths var-

Table 3. Mere-exposure effects modified by hostile media perceptions. Replications in different national subsamples.

\begin{tabular}{lccc}
\hline & $\begin{array}{c}\text { Countries with low } \\
\text { European identity }\end{array}$ & $\begin{array}{c}\text { Countries with } \\
\text { medium European identity }\end{array}$ & $\begin{array}{c}\text { Countries with high } \\
\text { European identity }\end{array}$ \\
\hline $\mathrm{n}=$ & $1,388 / 4,329 / 1,097$ & $1,004 / 3,798 / 1,323$ & $990 / 4,470 / 2,050$ \\
\hline Hostility & & beta coefficients & $.08^{* *}$ \\
Non-Hostility & .04 (n.s.) & $.12^{* * *}$ & $.12^{* * *}$ \\
Neutrality Perception & $.08^{* * *}$ & $.13^{* * *}$ & $.15^{* * *}$ \\
\hline
\end{tabular}

Note: ${ }^{* *}=p<.001 ;^{* *}=p<.01 ;^{*}=p<.05$ 
ied noticeably between the three country groups. The mere-exposure effect is much lower in countries where the citizens showed lower European identity while it is much more noticeable in countries with high European identity.

\section{Discussion}

Based on the results of several content analyses (De Vreese et al., 2011; Peter et al., 2003) of media coverage about the $\mathrm{EU}$, one might expect that higher exposure to media content about EU affairs might lead to a lower European identity. However, the results obtained in this study consistently showed the opposite. In almost all subsamples, we found (at least slight) significant positive effects. These findings support our theoretical assumption, that frequent contact with predominantly neutral information provokes mere-exposure effects, which promote the feeling of European identity. Even the unintended, casual contact with news on the EU provided by the media fostered European identity. These findings illustrate the importance of a continuous coverage on EU topics by the mass media for the development of a common European identity.

The results obtained also support our theoretical assumptions based on the hostile media theory, confirming both hypotheses. Nevertheless, it must be considered that the differences in effect-strength were just moderate. Particularly in countries in which the citizens had a higher European identity, the discrepancies were slight. If the citizens of a certain country predominantly felt attached to Europe (at least somewhat), the mereexposure effect was always relatively high, regardless of whether they perceived the media as hostile or not. This result was not obtained in countries where the majority of the citizens felt a low attachment to Europe. In these societies, the mere-exposure effect was just existent in people without hostile media perceptions. The effect disappeared in citizens who perceived the media as hostile. This finding points to the important role of media perception in media effects on European identity. Therefore, if European institutions aim to foster a common identity in countries with low levels of European identity, it is not enough that the citizens feel motivated to use the news about European issues provided by the media. It is even more important that media are perceived as neutral.

Finally, the results of the study also offer some room to speculate about the effects of media coverage on European identity, particularly in times of crisis. In the light of the results it can be reasoned that it is not necessary that a disintegrating event such as the Brexit or the Eurozone financial crisis immediately garner negative feelings about EU despite the excessive on-going negative media coverage. The reason for such an attribute is that identities are not constructed in a short period of time, rather it is a long term process (Cinpoes, 2008). Thus, a crisis that either remains in the media or lasts for short time may not affect people's feelings of attachment with the respective political system. Much more important seems to be how the media coverage is evaluated by the people in the respective countries. If people lose faith in the neutrality of media this could also affect the identification with the political collective. Thus, recent attacks from populists on the media's independency in many European countries might be an even more serious threat to European democracy than any critical comment of journalists about the performance of the EU.

\subsection{Limitations and Suggestions for Future Research}

In the present study, a secondary data analysis was applied, which has its own typical problems. The most significant limitation was that the analyses were confined within the boundaries of variables that could be deemed too imperfect to measure identity. Additionally, the available indicators of media use combined with the perceived relevance of these sources for news on the EU might be considered of questionable appropriateness in measuring the amount of contact with European issues. It might be argued that the respondents were not aware from which media they obtained news about EU affairs. Thus, the indicator did not measure an EU specific media use but instead indicated the general use of news on public affairs. If the available indicators did not measure EU-specific media use but political media use in general, it is arguable that the observed variable relationships could be interpreted as mere-exposure effects. Thus, to address this potential limitation, the dependent variable (EU identity) was replaced by indicators of national and local identity. The findings showed that in both cases, the effects almost disappeared. The beta-coefficients of the media use variable on national identity and local identity were quite small (beta $=.04$ ) respectively. Thus, it is reasonable to state that we observed a mere-exposure effect.

To operationalize media hostility, this study dealt with the evaluation of the performance of the EU. However, the evaluation of the EU is not necessarily the best indicator of partisanship. Better indicators of partisanship towards the EU would be highly desirable, such as political party (pro-Europe or Euroskeptic) affiliations of respondents, but they were not available in the Eurobarometer data. Furthermore, the hostility of the media towards the EU was measured by using only one indicator (the overall estimation of bias). In general, the hostile media research applies a fine-grained measurement of media hostility, including, for example, the individual estimation of the percentage of favorable or non-favorable references to one's position or the perception of the personal views of the journalists.

Despite this critique, the presented results show the relevance of media coverage on European issues for European identity even for those who are not intentionally searching for information and news on the EU. But the results also highlight which problems the EU will face if peoples' reliance on a neutral coverage of the media erodes or even disappears. 


\section{Acknowledgments}

We acknowledge support for the Article Processing Charge by the German Research Foundation and the Open Access Publication Fund of the Technische Universität Ilmenau.

\section{Conflict of Interests}

The authors declare no conflict of interests.

\section{References}

Agirdag, O., Phalet, K., \& Van Houtte, M. (2016). European identity as a unifying category: National vs. European identification among native and immigrant pupils. European Union Politics, 17(2), 285-302.

Alarcón, A. (2010). Media representation of the European Union: Comparing newspaper coverage in France, Spain and the United Kingdom. International Journal of Communication, 4, 398-415.

Anderson, B. (1991). Imagined communities: Reflections on the origin and spread of Nationalism. London: Verso.

Ball-Rokeach, S., \& Defleur, M. L. (1976). A dependency model of mass-media effects. Communication Research, 3(1), 3-21.

Brubaker, R., \& Cooper, F. (2000). Beyond "identity". Theory and Society, 29, 1-47.

Bruter, M. (2003). On what citizens mean by feeling 'European' : Perceptions of news, symbols and borderlessness. Journal of Ethnic and Migration Studies, 30(1), 21-39.

Bruter, M. (2005). Citizens of Europe? The emergence of a mass European identity. New York, NY: Palgrave Macmillan.

Carey, S. (2002). Undivided loyalties. Is national identity an obstacle to European integration? European Union Politics, 3(4), 387-413.

Cinpoes, R. (2008). Thematic articles-National and European identity. Journal of Identity and Migration Studies, 2(1), 1-14.

Corbett, S. (2016). The social consequences of Brexit for the UK and Europe: Euroscepticism, populism, nationalism, and societal division. International Journal of Social Quality, 6(1), 11-31.

D'Haenens, L. (2005). Euro-vision: The portrayal of Europe in the quality press. Gazette, 67(5), 419-440.

De Vreese, C. (2004). Primed by the Euro: The impact of a referendum campaign on public opinion and evaluations of government and political leaders. Scandinavian Political Studies, 27(1), 45-64.

De Vreese, C. (2007). The EU as a public sphere. Retrieved from http://www.europeangovernance-livingrevi ews.org/Articles/Ireg-2007-3/download/Ireg-2007-3 BW.pdf

De Vreese, C. H., \& Boomgaarden, H. G. (2006). Media effects on public opinion about the enlargement of the
European Union. Journal of Common Market Studies, 44, 419-436.

De Vreese, C., Boomgaarden, H. G., \& Semetko, H. A. (2011). (In)direct framing effects: The effects of news media framing on public support for Turkish membership in the European Union. Communication Research, 38(2), 179-205.

Delanty, G. (2014, February 28). European election specials. Retrieved from http://en.theeuropean.eu/ gerard-delanty/8002-the-europeanization-of-nation al-identity

Delanty, G., \& Rumford, C. (2005). Rethinking Europe: Social theory and the implications of Europeanization. London: Routledge.

Easton, D. (1965). A framework for political analysis. Englewood Cliffs, NJ: Prentice-Hall.

European Commission. (1973). Declaration on European identity. Brussels: European Commission.

Favell, A., \& Recchi, E. (2009). Pioneers of European integration. Northampton: Edward Elgar.

Fligstein, N., Polyakova, A., \& Sandholtz, W. (2012). European integration, nationalism and European identity. JCMS: Journal of Common Market Studies, 50(1), 106-122.

Gandemer, W. (2014). Prospects for European identity: A case study of third culture kids in Strasbourg. Groningen: University of Groningen.

Gellner, E. (1983). Nations and nationalism. Oxford: Blackwell.

Georgiou, M. (2006). Diaspora, identity and the media: Diasporic transnationalism and mediated spacialities. New York, NY: Hampton Press.

Gerhards, J., Odfferhaus, A., \& Roose, J. (2009). Wer ist verantwortlich? Die Europäische Union, ihre Nationalstaaten und die massenmediale Attribution von Verantwortung für Erfolge und Misserfolge. In F. Marcinkowski \& B. Pfetsch (Eds.), Politik in der Mediendemokratie: Politische Vierteljahresschrift Sonderheft (pp. 529-558). Wiesbaden: Verlag fuer Sozialwissenschaften.

Giner-Sorolla, R., \& Chaiken, S. (1994). The causes of hostile media judgements. Journal of Experimental Social Psychology, 30, 165-180.

Gripsrud, J. (2007). Television and the European public sphere. European Journal of Communication, 22(4), 479-92.

Gunther, A. C., \& Liebhart, J. L. (2006). Broad reach or biased source? Decomposing the hostile media effect. Journal of Communication, 56(3), 449-466.

Gunther, A. C., Christen, C. T., Liebhart, J. L., \& Chih-Yun Chia, S. (2001). Congenial public, contrary press, and biased estimates of climiate of opinion. Public Opinion Quarterly, 65(3), 295-320.

Habermas, J., \& Derrida, J. (2005). February 15, or what binds Europeans together: A plea for a common foreign policy, beginning in the core of Europe. Constellations, 10(3), 291-297.

Hansen, G. J., \& Kim, H. (2011). Is the media biased 
against me? A meta-analysis of the hostile media effect research. Communication Research Report, 28(2), 169-179.

Harmsen, R., \& Wilson, T. (2000). Europeanization: Institution, identities and citizenship. Amsterdam: Editions Rodopi.

Hart, P. S., Feldman, L., Leiserowitz, A., \& Maibach, E. (2015). Extending the impacts of hostile media perceptions: Influences on discussion and opinion polarization in the context of climate change. Science Communication, 37(4), 506-532.

Hillje, J. (2013). Saving Europe online? European identity and the European Union's Facebook communication during the eurozone crisis. London: Media @ LSE.

Hooghe, L., \& Marks, G. (2005). Calculation, community and cues: Public opinion on European integration. European Union Politics, 6(4), 419-443.

Hwang, H., Pan, Z., \& Sun, Y. (2008). Influence of hostile media perception on willingness to engage in discursive activities: An examination of mediating role of media indignation. Media Psychology, 11(1), 76-97.

Irimie, R. (2014). European identity vs national identity? The crisis of identification in the European Union. Târgu Mureș: University of Târgu Mureș.

John, M. (1861). Considerations on representative government. In G. William (Ed.), Utilitarism, on liberty, considerations on representative government ( $\mathrm{pp}$. 188-410). London: J. M. Dent.

Kaina, V., \& Karolewski, I. P. (2013). EU governance and European identity. Living Reviews in European Governance, 8(1), 1-59.

Kaitatzi-Whitlock, S. (2007). The missing European public sphere and the absence of imagined European citizenship. European Societies, 9(5), 685-704.

Koopmans, R., \& Statham, P. (2010). The making of a European public sphere: Media discourse and political contention. New York, NY: Cambridge University Press.

Maier, M., \& Risse, T. (2003). Europeanization, collective identitis and public discourses. Retrieved from http:// cordis.europa.eu/documents/documentlibrary/8260 8121EN6.pdf

Manners, I. (2002). Normative power Europe: A contradiction in terms. Journal of Common Market Studies, 40(2), 235-258.

Norris, P. (2000). A virtuous circle? The impact of political communications in post-industrial democracies. Cambridge: Cambridge University Press.

Olausson, U. (2010, June 14). Towards a European identity? The news media and the case of climate change. European Journal of Communication, 25(2), 138-152.

Perloff, R. M. (2015). A three-decade retrospective on the hostile media effect. Mass Communication and Society, 18, 701-729.

Perry, D. K. (1990). News reading, knowledge about, and attitudes toward foreign countries. Journalism Quarterly, 67, 353-358.
Peter, J., Semetko, H., \& de Vreese, C. (2003). EU Politics on television news. European Union of Politics, 4(3), 305-327.

Reuters Institute for the Study of Journalism. (2016, May 20). Study shows that majority of press coverage in EU referendum campaign was heavily skewed in favour of Brexit in first two months of campaign. Retrieved from http://reutersinstitute.politics.ox.ac.uk/ news/study-shows-majority-press-coverage-eu-refer endum-campaign-was-heavily-skewed-favour-brexit

Risse, T. (2003). The Euro between national and European identity. Journal of European Public Policy, 4, 487-505.

Risse, T. (2010). A community of Europeans? Transnational identities and public spheres. Ithaca, NY: Cornell University.

Rittberger, B., \& Maier, J. (2008). Shifting Europe's boundaries: Mass media, public opinion and the enlargement of the EU. European Union Politics, 9(2), 243-267.

Ruiz, J., Antonia, M., Górniak, J., Kosic, A., Kiss, P., \& Kandulla, M. (2004, July 29). European and national identities in EU's old and new member states: Ethnic, civic, instrumental and symbolic components. Retrieved from http://eiop.or.at/eiop/pdf/2004-011.pdf

Schneeberger, A. (2009, July). Constructing European identity through mediated difference: A content analysis of Turkey's EU accession process in the British press. PLATFORM: Journal of Media and Communication, 1, 83-102.

Schuck, A. R., Azrout, R., Boomgaarden, H., Elenbaas, M., van Spanje, J., Vliegenthart, R., \& de Vreese, C. (2011). Media visibility and framing of the European Parliamentary elections 2009: A media content analysis in 27 countries. In M. Maier, J. Strömbäck, \& L. L. Kaid (Eds.), Political communication in European parliamentary elections (pp. 175-198). Oxford: Routledge.

Semetko, H. A. (2004). Media, public opinion and political action. In J. Downing, D. McQuail, P. Schlesinger, \& E. A. Wartella (Eds.), The SAGE handbook of media studies (pp. 351-374). Thousand Oaks, CA: SAGE.

Shore, C. (2000). Building Europe. The cultural politics of European integration. London: Routledge.

Slater, M. D. (2007). Reinforcing spirals: The mutual influence of media selectivity and media effects and their impact on individual behavior and social identity. Communication Theory, 17(3), 281-303.

Smith, A. (1992). National identity and the idea of European identity. Oxford: Blackwell.

Staehelin, K. P. (2016). Drivers of change? Media effects on the identity and utilitarian EU attitude dimensions. Amsterdam: University of Amsterdam.

Stone Sweet, A., Sandholtz, W., \& Fligstein, N. (2001). The institutionalization of Europe. Oxford: Oxford University Press.

Stråth, B. (2002). A European identity: To the historical limits of a concept. European Journal of Social Theory, 5(4), 387-401. 
Suszycki, A. M. (2006). European identity in Sweden. In I. P. Karolewski \& V. Kaina (Eds.), European identity: Theoretical perspectives and empirical insights (pp. 179-208). Berlin: LIT Verlag.

Szczerbiak, A., \& Taggart, P. (2008). Opposing Europe?. Oxford: Oxford University Press.

Thompson, J. (1995). The media and modernity: A social theory of the media. Cambridge: Polity Press.

Trenz, J. H. (2007). 'Quo vadis Europe?' Quality newspapers struggling for European unity. In J. Fossum \& P. Schlesinger (Eds.), The European Union and the public sphere (pp. 89-109). London: Routledge.

Triga, V., \& Vadratsikas, K. (2016). The impact of media representations of the EU and its policies on European identity. Limassol: COHESIFY Project.

Tsfati, Y., \& Cohen, J. (2005). Democratic consequences of hostile media perceptions: The case of Gaza settlers. The Harvard International Journal of Press/Politics, 10(4), 28-51.

Vallone, R. P., Ross, L., \& Lepper, M. R. (1985). The hostile media phenomenon: Biased perception and percep- tions of media bias in coverage of Beirut massacre. Journal of Personality and Social Psychology, 49(3), 577-85.

Walkenhorst, H. (2008). Constructing the European identity-Trap or gap? European integration between community-building and path-dependency. Retrieved from http://www.ul.ie/ppa/content/files/ Walkenhorst_constructing.pdf

Walkenhorst, H. (2009). The conceptual spectrum of European identity: From missing link to unnecessary evil. Limerick: University of Limerick.

Wendt, A. (1999). Social theory of international politics. Cambridge: Cambridge University Press.

Wodak, R. (2004). National transnational identities: European and other identities constructed in interviews with EU officials. In R. K. Herrmann, T. Risse, \& M. B. Brewer (Eds.), Transnational identities: Becoming European in the EU (pp. 97-128). Lanham: Rowman \& Littlefield.

Zajonc, R. B. (2001). Mere exposure: A gateaway to the subliminal. Current Directions in Psychological Science, 10(6), 224-228.

\section{About the Author}
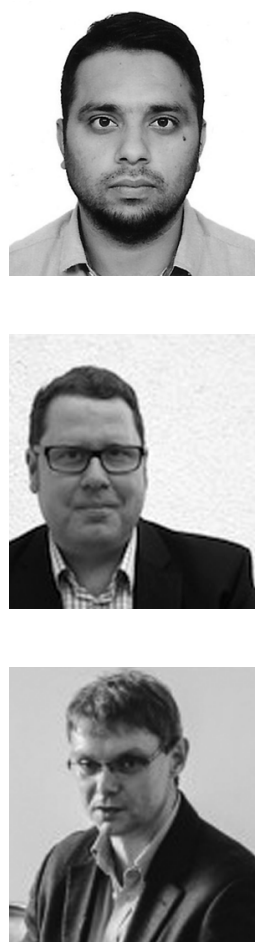

Waqas Ejaz. 2005-2009 studied Mass Communication in University of Punjab, Pakistan. 2010-2012 completed MA in Communication Studies from Technische Universität Ilmenau. Since 2013 working as research assistant in Technische Universität Ilmenau and writing his doctoral thesis, Understanding Relationship and Effects of Media on European Identity: A Study Based on Secondary Analysis of Eurobarometer Data.

Marco Bräuer. 1998-2004 Studies in Media and Communication Studies at Technische Universität IImenau. 2004-2006 research assistant at Zebralog - medienübergreifende Dialoge, Berlin. 2006-2010 research assistant at Kassel University. 2009-2016 research assistant at Technische Universität Ilmenau. Doctoral Thesis: Energy System Transition and Protests: A Study of the Communication Strategies of Protestors Against the Extension of the German High Voltage Power Grid. Since 2016 consultant at the Federal Office for the Family and Civil Society Tasks.

Jens Wolling. 1987-1993 Studies of Communication Science at the University of Berlin (FU Berlin). 1993-1998 research assistant at the University of Dresden. Doctoral Thesis: Media Effects on Political Alienation? 1999-2003 assistant professor at the University of Ilmenau. 2003-2006 Professor at the University of Munich (LMU München). Since 2006 Professor for Communication Research and Political Communication at the University of IImenau. 